\title{
Online Methods in Geography Educational Research
}

\author{
Clare Madge* and Henrietta O’Connor**
}

*Department of Geography, University of Leicester, Leicester LE1 7RH.

Email: CM12@le.ac.uk

** Centre for Labour Market Studies, University of Leicester, Leicester LE1 7RH.

Email: $\underline{\text { HSO1@le.ac.uk }}$ 
Online Methods in Geography Educational Research 


\section{Online Methods in Geography Educational Research}

\section{Introduction}

Geographers are fully engaged in the debate surrounding the impact of new information and communication technologies (ICT) and there has been a proliferation of research on the impact of ICT on geographical education. This includes analyses of how ICT may affect geographical learning paradigms (Hill and Solem, 1999; Rich et al., 2000; Solem, 2000) and the role of multimedia in enhancing learning and teaching in geography (Castleford, et al., 1998; Johnson, 2002; Lemke and Ritter, 2000; O’Tuathail and McCormack, 1998; Reed and Mitchell, 2001; Shroder et al., 2002; Vincent, 2000). Specific studies on ICT and geography higher education include discussions on the value of web-based resources (Gardner, 2003), the role of virtual fieldtrips (Stainfield et al., 2000) and cultivating study skills in web-based environments (Goett and Foote, 2000). Furthermore, there is a considerable and growing body of research exploring how online learning can enhance higher education more generally (Bennett et al., 1999; Carmichael and Honour, 2002; Davenport, 2001; Ehrmann, 1995; Housego and Freeman, 2000; Lapadat, 2002; Mason, 2002; Singh et al., 2003; Speck, 2000). The results of such studies are mixed. Lapadat (2002), for example, takes a positive view, stressing that the interactive nature of online learning fosters constructivist learning environments in which the learner's conceptual development occurs through practical experience, discussion and problem solving. By contrast, Speck (2000) is more critical, arguing that the academy has embarked upon the commercialisation of online courses without giving sufficient attention to training and academic integrity.

Yet despite this expansion of work into the virtual geographic world, less has been written about the potential of ICT as a medium of research for geographers in higher education. This is surprising given the great methodological potential and versatility they can provide for educational research: they have the ability to mitigate the distancing of space; they are useful in internationalising research without adding costs to the funding body; and they can be used to contact groups often difficult to reach, such as the less physically mobile (Paciello, 2000). The limited uptake of online methods is partly owing to the perceived technical expertise required to use them. The aim of this paper therefore, is to disseminate information on the use, strengths and 
weaknesses of online research methods, in the hope of increasing research capacity within the geographical international community.

\section{Types of Online Research Methods}

Few geographers have used online research methods but it is widely acknowledged in other social sciences, for example in sociology, psychology and mass communications, that ICT offer researchers novel ways of creating and obtaining data. There are three main types of online research methods currently used that are relevant to geographers. The choice of research method will depend on the specific aims of the research.

\section{Web-based Questionnaires/Electronic Surveys}

Web-based questionnaires and email surveys can provide fast and cheap alternatives to postal, face-to-face and telephone surveys. Web-based questionnaires are designed as web pages and located on a host site. Electronic surveys involve questions being sent as part of the email itself. Alternatively, a questionnaire designed in word processing or spreadsheet software can be attached to an email. The type of data yielded is quantitative and with a web-based questionnaire data can be loaded automatically into a spreadsheet or database increasing the speed and accuracy of data collection. Numerous examples of web-based questionnaires and electronic surveys exist in the literature (Coomber, 1997; Hampton and Wellman, 1999; Kaye and Johnson, 1999; Litvin and Kar, 2001; Madge and O’Connor, 2002; Roberts and Parks, 2001; Schaefer and Dillman, 1998; Selwyn and Robson, 1998; Smith, 1997; Witmer et al., 1999). More recent references compare online and onsite surveys (McDonald and Adam, 2003; Riva et al., 2003).

\section{Online Interviews/Virtual Focus Groups}

Virtual interviews can be conducted over the Internet enabling inclusion of participants from a wide geographical area whilst saving time and travel costs. There are two main types of online interviews: asynchronous and synchronous. Asynchronous or `non real 
time' exchanges are most common and are usually conducted via email or a listserv facility (bulletin boards or chatrooms) with 12 to 20 respondents. Gaiser's (1997) online focus groups, for example, were conducted in a listserv environment which can be used to advantage where all expected participants are regular listserv users, thus eliminating the need to set up mutually convenient chat times. However, it is not a 'real time' facility, respondents can post their reply at anytime and as such the facilitator cannot play an active role in moderating the interview. Greater spontaneity, group interaction and high levels of immediacy and engagement on the topic can only occur during 'real time' synchronous online interviews. Examples of virtual interviews include Alder and Zarchin (2002), Chen and Hinton (1999), Mann and Stewart (2000) and Sweet (2001). Research comparing face-to-face and virtual interviews include Curasi (2001) and Schneider et al. (2002). The qualitative data that is gained from virtual interviews is already in a text format and can be saved directly to file, reducing transcription time and costs.

\section{Virtual Ethnographies}

Interest in online cultures and communities has resulted in virtual ethnographies (Hine, 2000) of cyberspace cultures. These include detailed studies on particular online communities such as electronic cafes (Correll, 1995), feminist support groups (Ward, 1999) and computer-mediated fan clubs (Baym, 1997). More general ethnographies have also been conduced on virtual reality technologies (Green, 1999), types of computer mediated communications (Soukup, 1999) and online identities (Turkle, 1995). Country studies include Miller and Slater's (2000) work on Trinidad. Methods used in virtual ethnographies range from systematic observation of online communities, laboratory experiments in computer mediated communication and production of webographies (see Hine 2000 for detailed discussion). Numerous ethical issues arise from using unobtrusive techniques as detailed by Paccagnella (1997). The type of data gained is qualitative, in-depth and contextual. Virtual ethnographies are often undertaken in conjunction with place-based onsite ethnographies to explore the intersection of real and virtual communities (Wakeford, 1999). 


\section{Applying Online Research Methods: the Cyberparents Example}

Two online methods we have used successfully in our research are outlined below. These draw on the experience of a recent Internet-based Cyberparents research project (http://www.geog.le.ac.uk/baby/) which was initiated to examine how, why and in what ways new parents use the Internet as an information source about parenting and as a form of social support. Online methods were considered the most appropriate research tools for investigating this online community. A web-based questionnaire survey was used to identify general patterns of use of one specific parenting website, Babyworld (http://www.babyworld.co.uk), while more in-depth data were gathered from the website users through semi-structured synchronous virtual group interviews conducted using a software conferencing technique - Hotline Connect. As we hope to show, these online research methods could be usefully applied in geography educational research.

\section{Web-based Questionnaire Survey}

The first stage of the project involved setting up an online survey with an associated project website to glean general information about usage patterns of Babyworld. This online method was selected for several reasons: it would rapidly reach a wide audience; it was quicker and cheaper than postal mail, faxes and phone; and responses could be received around the clock and directly loaded into an automatic analytical package, ensuring that the data were received in a consistent and predictable format. Additionally, web-based surveys provide a far superior questionnaire interface to email surveys and it is possible to make them more user friendly and attractive, thus encouraging higher response rates. The web-based survey can also be included on a dedicated website which can be used as a platform to provide more information about the project, the researchers and the affiliated institution.

The questionnaire survey (http://www.geog.le.ac.uk/baby/babyworldform.asp) was created using the html compiler 'Adobe GoLive 4.0' and followed a similar format to traditional self-completion postal questionnaires, the main difference being that the survey form was set up online. The questionnaire was designed to be simple (24 questions) and quick (10 minutes) to fill in and included tick box yes/no questions, ranking attitudinal questions and open-ended responses. The survey ended with a short 
message to thank the respondents and a request to email the researchers through the direct link if the respondent was willing to participate in a further detailed online interview. A response database was set up on the departmental server to collect the completed questionnaire data in Microsoft Access, directly ready for analysis.

In order to administer the questionnaire a series of webpages were developed (http://www.geog.le.ac.uk/baby/). All pages included the University of Leicester crest to show institutional affiliation, to give the project credibility and ensure the participants could verify our status. The website included a homepage with a brief introduction to the project, which was linked to further pages entitled 'meet the researchers' (http://www.geog.le.ac.uk/baby/meet.html) and 'more about the project' (http://www.geog.le.ac.uk/baby/more.html). The final page was the questionnaire survey. Several hotlinks were created between the questionnaire, the Cyberparents website and Babyworld website. The links from Babyworld to the research webpages were made at the suggestion of the website providers and positioned strategically in prime locations on the Babyworld home page and the most used pages of the website. The hotlink included an icon (parent holding child's hand) and a question `are you a cyberparent? Click here if you can help interest and us' which we hoped would intrigue users sufficiently to click on the icon. This was the only mechanism to elicit responses. It is significant to note that without the agreement and co-operation of the website providers to place strategic hypertext links, the survey would most certainly not have been successful since it would have been impossible to recruit these specific online community members in any other way. Thus the issue of access to online communities and website providers is crucial when conducting online research. As Coomber (1997) has highlighted, there is little point in having a web page and setting up an online survey and passively 'waiting' for eligible respondents to find the site: more active enrolment is needed to encourage users to complete an online survey. In this case the significance of having the site providers 'on our side' cannot be underestimated. In the case of educational research, however, these questions may be less pressing, particularly if the research site is a virtual learning environment (VLE) where registration, and perhaps even participation, are compulsory.

\section{Online Synchronous Interviews}


The second stage of the research process involved semi-structured synchronous virtual group interviews to gain more detailed understanding of the key themes emerging from the questionnaire data. The first task was to find a convenient way to carry out these interviews. It was immediately apparent that face-to-face (FTF) interviews would be impractical, costly and time consuming because our respondents were geographically widely dispersed. Apart from the distance factor, both the researchers and the respondents had young children and/or were pregnant, making the 'traditional' interview unfeasible. As this research focused explicitly on Internet usage, our interviewees were already, by definition, Internet users and likely to be familiar with virtual communication methods. An Internet based interview forum seemed to be a logical, low cost, convenient and innovative research method.

'Hotline Connect' was selected to develop the `real time’ interview forum. It is a user-friendly application, available for both Apple Macintosh and Microsoft Windows based platforms. It enables users to chat, either in groups or one-to-one, to others simultaneously logged on to a specified server address. The software allows the facilitator to have a high degree of control over the proceedings: it is not possible for anyone to 'lurk'; users must identify themselves and the facilitator has the ability to disconnect those who are non-identified; and it is not possible to 'drop in' to the sessions because they take place at specified times known only to those invited by the facilitator. Moreover, Hotline Connect does not have high power requirements and can be installed and used easily without the need for sophisticated hardware or a high level of technical ability. This was important to us because we were already reliant on the goodwill of the interviewees for modem live time and the motivation to install the software and so the process needed to be as simple as possible. Indeed, only one participant dropped out at the installation stage because, unexpectedly, her computer was not able to run the software. Overall there were few glitches in the use of the conferencing software, although one respondent in Malaysia had her link interrupted owing to transmission problems which disrupted the interview process. The final interview transcript was saved and immediately transferred to a Word file saving transcription time and cost.

\section{Strengths and Weaknesses of Online Research Methods}


The success of online research methods has been varied (Illingworth, 2001; Madge and O’Connor, 2002; Seymour, 2001; Wilson and Laskey, 2003). There are, however, numerous general advantages of online research methods. They enable the researcher to contact a geographically dispersed population and so can be useful in internationalising research. They can also be used to contact groups often difficult to reach, such as the less physically mobile (disabled/in prison/in hospital) or the socially isolated (drug dealers/terminally ill/ etc). Savings in costs are also to be recommended (for example, costs associated with travel, venue, data entry for questionnaires, transcription of interviews). Moreover, according to Denscombe (2003, p. 51), the quality of responses gained through online research is much the same as responses produced by more traditional methods, warranting 'guarded optimism’ about the validity of these new methods.

Additionally, advantages are also evident when considering specific online methods. Using web-based surveys, for example, enables the researcher to collect large volumes of data quickly and at low cost. Harris (1997), for example, reports that most completed online surveys are returned within 48-72 hours, making turnaround incredibly fast compared to onsite methods. Data can also be analysed continuously and directly imported into statistical tools and databases, increasing speed and accuracy of analysis. Anonymity can also be helpful for some topics as Harris (1997) suggests, interviewer bias is reduced or eliminated in online surveys. There is some debate about response rates of online questionnaires but recent research suggests that postal questionnaires and web-based surveys produce similar response rates and email might actually be preferred where there is an option (Truell, et al., 2002).

Regarding synchronous virtual interviews, advantages include the fact that they enable people in different places to operate as a group, they can be a useful forum for asking sensitive/embarrassing questions and they can be more convenient for the respondent, usually being completed at home at a time suitable to them. As Pring (1995, quoted in Dodd, 1998, 62) summarises: `...online discussion can provide very alive and participatory forums. They offer new levels of immediacy- respondents can be anywhere in the world- and transcripts are available instantly.' Compared to face-toface interviews where particular individuals usually dominate the discussion, online interviews display more uniform participation levels (Schneider et al., 2002). There is also a tendency to be less inhibited online and respondents are more direct in stating 
their opinions, and less likely to edit their thoughts to give socially desirable answers. This results in the potential of greater equality between respondents in an online interview situation.

However, despite its promise, some limitations of online research are coming to light. A major limitation is that the 'digital divide' means that some regions of the world and some educational groups will be less 'connected' than others as some individuals by virtue of their circumstances (nationality, income, age, ethnicity, gender) may not have access to computer equipment, software and literacy or Internet connections (Janelle and Hodge, 2000; Loader, 1998). Internet research may involve sample bias and be non-representative, although issues of access and technical expertise are softened in the case of educational research in the 'developed' world because universities provide computers and most students now have access, if not ownership, of computers.

Additionally, disadvantages are also evident when considering specific online methods. Online surveys, for example, may have to be shorter than those conducted onsite. Response rates drop off after 10-15 questions and are directly and negatively correlated with questionnaire length (Harris, 1997). It is also reported that online surveys have lower overall response rates than onsite surveys, Witmer et al (1999) suggesting response rates of $10 \%$ or lower being common. There are also notable problems with the use of virtual synchronous interviews. As Selwyn and Robson (1998) have noted, when moving the traditional interview to an electronic arena, the interviewer requires a very different set of skills. For example, in the virtual interview all subtle visual non-verbal cues are lost and rapport must be built without these through the use of high levels of self-disclosure and online emoticons. Because of this it has been found that smaller groups (6 to 8 respondents) are required for virtual focus groups compared to face-to-face focus groups (Harris, 1997). Other aspects of the virtual medium also present challenges to the researcher, for example the speed of typing dominates online interactions rather than most vocal personalities, changing the nature of group interactions. Finally, the virtual interface presents new challenges to all involved: not only is the researcher reliant on the participant having access to a suitable computer but s/he is also dependent on a considerable level of motivation, interest and technical knowledge on the part of the interviewees. There is, for example, some evidence to suggest that that there are higher rates of attrition with online focus groups than with face-to-face focus groups, so over recruitment is necessary (Harris, 1997). 
Sweet (2001) recommends 50 to 100 percent more respondents are recruited than the final desired number.

\section{Conclusions}

Given the growth and impact of the Internet in recent years, the ability to utilise online research methods is both timely and of utmost significance to geographers in higher education. Their use, however, must be carefully considered. As Denscombe (2003, p.41) suggests: `A decision on whether it is appropriate to use `e-research' should be based on an. ...evaluation of the respective advantages and disadvantages in relation to the specific topic that is to be investigated.' Indeed, although the data collected by online methods can be rich and valuable to the researcher, the potential of online research should not be exaggerated: many of the issues and problems of conventional research methods still apply in the virtual venue. As Smith (1997, p.4) concludes: 'The new technology offers a spate of problems layered over the old.' Caution should be stressed in an attempt to avoid the ‘cyberbole’ (Imken, 1999) and overdrawn opposition between `real’ and virtual techniques. As Illingworth (2001) suggests, we should avoid the use of the Internet as an `easy option’ and '...encourage a more developed focus on the justification, applicability and benefits of Internet research to a particular project. What has become apparent is that the effectiveness of CMC (computer mediated communication) is much dependent on who is being researched, what is being researched and why.'

Despite these cautions, there are instances reported of online research being used very effectively in educational research. Cousin and Deepwell (2002) report on the use of quantitative and qualitative online methods to evaluate online student learning. Examples include online surveys being used to assess innovative teaching methods and to gather tutor experiences of their use and perceptions of online learning. Such surveys have been very useful for providing anonymous responses, high levels of expressiveness and reducing respondent fatigue through rapid keyboard use (Cousin and Deepwell, 2002, p. 200). The potential of virtual ethnographies for educational research has also been investigated by Turner (2000). He suggests that this online research method may be best used in conjunction with face-to-face methods. Employing this approach, Turner (2000) combined an online ethnographical analysis of the nature 
of contributions to an online student discussion forum, with face-to-face in depth interviews of student evaluations of this discussion facility. This 'triangulation' of online and face-to-face methods produced a more problematic and nuanced analysis of the nature of online learning, suggesting that a mixed methodology approach may be the most fruitful avenue for geography education research.

\section{Guidelines for Using Online Research Methods}

Several specialist textbooks on online research have recently been published to help first time online researchers (Chen and Hall, 2003; Coombes, 2001; Hewson et al., 2002; Jones, 1999; Mann and Stewart, 2000).

The following websites also give very useful information:

1. The ESRC-funded Virtual Methods Seminar Series promotes debate and sharing of expertise on the use of new information and communication technologies in social research (http://www.brunel.ac.uk/depts/crict/vmesrc.htm). It includes a biography page (www.brunel.ac.uk/depts/crict/vmbiog.htm), a mailing list associated with the seminar series (to join, visit $\underline{\text { JISCMAIL) and resources }}$ (http://www.brunel.ac.uk/depts/crict/vmlist.htm).

2. Social Research Update is a newsletter resource for social scientists interested in keeping up with methodological changes. See issue 4 on exploring the Internet, issue 20 on finding information on the WWW and issue 21 on email as a research tool (www.soc.surrey.ac.uk/sru).

3. WebUse is hosted by the University of Maryland as a portal for Internet researchers with several useful online tools available (www.webuse.umd.edu).

4. A webpage designed to help teachers and students is hosted by Ohio State University (http://ccl.english.ohiostate.edu/handouts/webresearch/searching/research_methods_literature.htm).

5. In an overview of methodological issues of online experiments in experimental psychology see

(http://www.psychologie.unizh.ch/genpsy/Ulf/Lab/WWWExpMethod.html). 


\section{Acknowledgements}

Parvati Raghuram and Jane Wellens have made valuable contributions to this paper. 


\section{REFERENCES}

Alder, C.L. and Zarchin, Y.R. (2002) The 'virtual focus group': using the Internet to reach pregnant women on home bed rest, Journal of Obstetric, Gynecologic and Neonatal Nursing, 31, pp.418-427.

Baym, N.K. (1997) Interpreting soap operas and creating community: inside a computer-mediated fan club, in: Kiesler, S. (ed) Culture of the Internet, pp. 103-120, (New Jersey, Lawrence Erlbaum Associates).

Bennett, S., Priest, A. and Macpherson, C. (1999) Learning about online learning: an approach to staff development for University teachers, Australian Journal of Educational Technology, 15, pp.207-221.

Carmichael, P. and Honour, L. (2002) Open source as appropriate technology for global education, International Journal of Educational Development, 22, pp.147-53.

Castleford, J., Robinson, G., Charman, D., Elmes, A., Towse, R.J., Garside, P., Browne, T., Funnell, D., Burkill, S., Gratton, J., Whalley, W.B., Rea, B.R. and Crampton, J. (1998) Arena symposium: evaluating IT-based resources for supporting learning and teaching in Geography: some case studies, Journal of Geography in Higher Education, 22 (3), pp. 375-423.

Chen, P. and Hinton, S.M. (1999) Realtime interviewing using the World Wide Web, Sociological Research Online, 4, 3, (http://www.socresonline.org.co.uk/socresonline/4/3/chen.html).

Chen, S.S. and Hall, J. (eds) (2003) Online Social Research: Methods Issues and Ethics, (New York, Peter Lang).

Coomber, R. (1997) Using the Internet for survey research, Sociological Research Online, 2, 2, (http://www.socresonline.org.uk/socresonline/2/2/2.html).

Coombes, H. (2001) Research Using IT, (Hampshire, Palgrave). 
Correll, S. (1995) The ethnography of an electronic bar: the lesbian café, Journal of Contemporary Ethnography, 24, pp. 270-298.

Cousin, G. and Deepwell, F. (2002) Research and evaluating online learning, in: Gibbs, G. and Rust, C. (eds) Improving Student Learning Using Learning Technologies, pp. 195-202, (?, OCSLD).

Curasi, C.F. (2001) A critical exploration of face-to-face interviewing versus computermediated interviewing, International Journal of Market Research, 43 (4), pp.361-375.

Davenport, R.J. (2001) Are we having fun yet? Joys and sorrows of learning online, Science, 293 (5535), pp.1619-1620.

Denscombe, M. (2003) The Good Research Guide, (Maidenhead, Open University Press).

Dodd, J. (1998) Market research on the Internet- threat or opportunity? Marketing and Research Today, 26 (1), pp. 60-66.

Ehrmann, S. (1995) Asking the right question: what does research tell us about technology and higher learning?

(http://www.learner.org/edtech/rscheval/rightquestion.html).

Gaiser, T. (1997) Conducting on-line focus groups: a methodological discussion, Social Science Computer Review, 15, pp.135-44.

Gardner, A. (2003) Discovering networked information in the Internet age: the JISC resource guide to geography and the environment, Journal of Geography in Higher Education, 27 (1), pp.103-108.

Goett, J.A. and Foote, K.E. (2000) Cultivating student research and study skills in webbased learning environments, Journal of Geography in Higher Education, 24 (1), 92-99. 
Green, N. (1999) Disrupting the field: virtual reality technologies and 'multisited' ethnographic methods, American Behavioural Scientist, 43, pp. 409-421.

Hampton, K.N. and Wellman, B. (1999) Netville online and offline: observing and surveying a wired suburb, American Behavioural Scientist, 43, pp. 464-474.

Harris, C. (1997) Developing online market research methods and tools, Paper presented to ESOMAR Worldwide Internet Seminar, Lisbon July 1997 (http://www.metamorphlab.com/lisbon-paper.html).

Hewson, C., Yule, P., Laurent, D. and Vogel, C. (2002) Internet Research Methods, (London, Sage).

Hill, A.D. and Solem, M.N. (1999) Geography on the Web: changing the learning paradigm? Journal of Geography, 98, pp.100-107.

Hine, C. (2000) Virtual Ethnography, (London, Sage).

Housego, S. and Freeman, M. (2000) Case Studies: integrating the use of web based learning systems into student learning, Australian Journal of Educational Technology, 16 (3), pp. 258-282.

Illingworth, N. (2001) The Internet matters: Exploring the use of the Internet as a research tool, Sociological Research Online, 6, 2, (http://www.socresonline.org.uk/6/2/illingworth.html).

Imken, O. (1999) The convergence of virtual and actual in the global matrix: artificial life, geo-economics and psychogeography, in: Crang, M. Crang, P. and May, J. (eds), Virtual Geographies, pp. 92-106, (London, Routledge).

Janelle, D.G. and Hodge, D.C. (2000) Information, place, cyberspace and accessibility, in: Janelle, D.G. and Hodge, D.C. (eds) Information, Place and Cyberspace, pp. 3-12, (New York, Springer). 
Johnson, N. (2002) Animating geography: multimedia and communication, Journal of Geography in Higher Education, 26, pp.13-18.

Jones, S. (ed) (1999) Doing Internet Research: Critical Issues and Methods for Examining the Net, (London, Sage).

Kaye B.K. and Johnson T.J. (1999) Research methodology: taming the cyber frontier: techniques for improving online surveys, Social Sceince Computer Review, 17 (3), pp. 323-337.

Lapadat, J. (2002) Written interaction: a key component in online learning, Journal of Computer-Mediated Communication, 7, 4 (http://www.ascusc.org/jcmc/vol7/issue4/lapadat.html)

Lemke, K.A. and Ritter, M.E. (2000) Virtual geographies and the use of the Internet for learning and teaching geography in Higher Education, Journal of Geography in Higher Education, 24, pp. 87-91.

Litvin, S.W. and Kar, G.H. (2001) E-surveying for tourism research: legitimate tool or a researcher’s fantasy? Journal of Travel Research, 39, pp. 308-314.

Loader, B.D. (1998) Cyberspace Divide. Equality, Agency and Policy in the Information Age, (London, Routledge).

McDonald, H. and Adam, S. (2003) A comparison of online and postal data collection methods in marketing research, Marketing Intelligence and Planning, 21, pp. 85-95.

Madge, C. and O’Connor, H. (2002) Online with the e-mums: exploring the Internet as a medium for research, Area, 34, pp. 92-102.

Mann, C. and Stewart, F. (2000) Internet Communication and Qualitative Research, (London, Sage). 
Mason, R. (2002) The global classroom, in: Adelsberger, H. Collis, B. and Pawlowski, J. (eds) Handbook on Information Technologies for Education and Training, pp.615622 (Berlin, Springer).

Miller, D. and Slater, D. (2000) The Internet: an Ethnographic Approach, (Oxford, Berg).

O'Tuathail, G. and McCormack, D. (1998) The technoliteracy challenge: teaching globalisation using the Internet, Journal of Geography in Higher Education, 22 (3), pp. 347-362.

Paccagnella, L. (1997) Getting the seat of your pants dirty: strategies for ethnographic research on virtual communities, Journal of Computer Mediated Communication, 3, 1, (http://www.ascusc.org/jcmc/vol3/issue1/paccagnella.html).

Paciello, M. (2000) Web Accessibility for People with Disabilities, (Kansas, CMP Books).

Pring, D. (1995) All wired up and ready to go? Market research in cyberspace, Reported in Proceedings of 1995 ESOMAR/ARF/JMA triad Conference, New York, June $11^{\text {th }}$ $14^{\text {th }}$.

Reed, M. and Mitchell, B. (2001) Using information technologies for collaborative learning in Geography: a case from Canada, Journal of Geography in Higher Education, 25 (3), pp. 321-340.

Riva, G., Teruzzi, T. and Anolli, L. (2003) The use of the Internet in psychological research: comparison of online and offline questionnaires, CyberPsychology and Behavior, 6, pp. 73-80.

Rich, D.C., Pitman, A.J. and Gosper, M.V. (2000) Integrated IT-based geography teaching and learning: A Macquarie University case study, Journal of Geography in Higher Education, 24 (1), pp. 116-122. 
Roberts, L.D. and Parks, M.R. (2001) The social geography of gender switching in virtual environments on the Internet, in: Green, E. and Adam, A. (eds) Virtual Gender: Technology, Consumption and Gender, pp. 265-285 (London, Routledge).

Schaefer, D. and Dillman, D.A. (1998) Development of a standard e-mail methodology: results of an experiment, Public Opinion Quarterly, 62, pp.378-397.

Schneider, S.J., Kerwin, J. Frechtling, J. (2002) Characteristics of discussion in online and fact-to-face focus groups, Social Science Computer Review, 20 (1), pp.31-42.

Selwyn, N. and Robson, K. (1998) Using email as a research tool, Social Research Update, Issue 21, University of Surrey (http://www.soc.surrey.ac.uk/sru/SRU21.html).

Seymour, W. (2001) In the flesh or online? Exploring qualitative research methodologies, Qualitative Research, 1, pp.147-168.

Singh, G., O’Donoghue, J. and Betts, C. (2003) A UK study into the potential effects of virtual education: does online learning spell an end for on-campus learning? Behaviour and Information Technology, 21, pp. 223-229.

Shroder, J.F., Craiger, J.P., Bishop, M.P. and Olsenholler, J. (2002) Geomorphology and the World Wide Web, Geomorphology, 47, pp.343-363.

Smith, C. (1997) Casting the net: surveying an Internet population, Journal of Computer Mediated Communication, 3, 1, (http://jcmc.huji.ac.il/vol3/issue1/smith.html).

Solem, M.N. (2000) The virtual geography department: assessing an agent of change in geography education, Journal of Geography in Higher Education, 24, pp. 353-364.

Soukup, C. (1999) The gendered interactional patterns of computer-mediated chatrooms: a critical ethnographic study, The Information Society, 15, pp. 169-176. 
Speck, B.W. (2000) The academy, online classes and the breach in ethics, New Directions for Teaching and Learning, 84, pp.73-82.

Stainfield, J., Fisher, P. Robinson, G. and Bednarz, R.S. (2000) International virtual fieldtrips: a new direction? Journal of Geography in Higher Education, 24, pp. 255262.

Sweet, C. (2001) Designing and conducting virtual focus groups, Qualitative Market Research: an International Journal, 4, pp.130-135.

Truell, A.D., Bartlett, J.E. and Alexander, M.W. (2002) Response rate, speed and completeness: a comparison of internet-based and mail surveys, Behaviour Research Methods, Instruments and Computers, 34 (1), pp. 46-49.

Turkle, S. (1995) Life on the Screen: Identity in the Age of the Internet, (New York, Touchstone).

Turner, A. (2000) Mickey Mouse and Football, Unpublished paper, ELATE, April 2001.

Vincent, P. (2000) Computer-mediated communication in undergraduate teaching: Web-based conferencing with lotus notes/domino, Journal of Geography in Higher Education, 24, pp. 381-394.

Wakeford, N. (1999) Gender and the landscapes of computing in an Internet café, in: Crang, M., Crang, P. and May, J. (eds) Virtual Geographies, pp.178-202 (London, Routledge).

Ward, K.J. (1999) Cyber-ethnography and the emergence of the virtually new community, Journal of Information Technology, 14 (1), pp. 95-105.

Wilson, A. and Laskey, N. (2003) Internet based marketing research: a serious alternative to traditional research methods? Marketing Intelligence and Planning, 21, pp. 79-84. 
Witmer, D.F., Colman, R. and Katzman, S.L. (1999) From paper-and-pencil to screenand-keyboard: towards a methodology for survey research on the Internet, in: Jones, S. (ed) Doing Internet Research: Critical Issues and Methods for Examining the Net, pp. 145-161, (London, Sage). 